
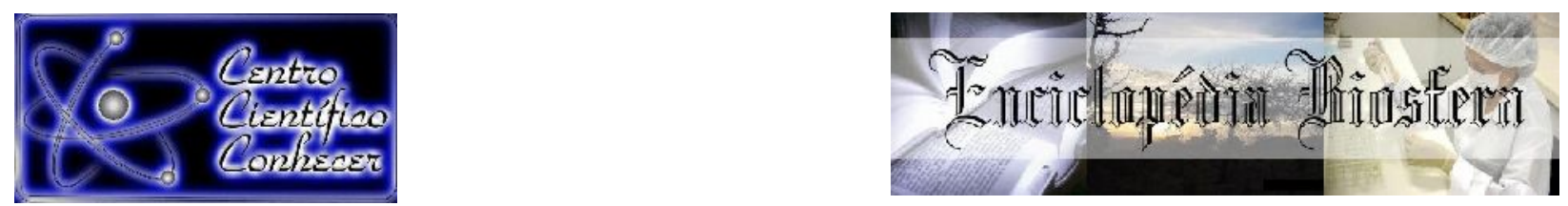

\title{
DESFAZIMENTO DE BENS MÓVEIS PERMANENTES DE TI EM UMA UNIVERSIDADE FEDERAL DO RECÔNCAVO DA BAHIA - UFRB
}

\section{Leila Selles Silva Lima', Andréa Jaqueira da Silva Borges ${ }^{2}$ \\ ${ }^{1}$ Mestre em Desenvolvimento Regional e Meio Ambiente - Faculdade Maria Milza (FAMAM). Contadora da Universidade Federal do Recôncavo da Bahia (UFRB), \\ Cruz das Almas-BA, Brasil. E-mail: leilaselles@ufrb.edu.br \\ ²Doutora em Geologia Ambiental - Universidade Federal da Bahia (UFBA). Mestre em Solo e Água (UFBA) e Especialista em Metodologia da Pesquisa. Docente da graduação e do Programa de Mestrado Profissional em Desenvolvimento Regional e Meio Ambiente da Faculdade Maria Milza (FAMAM), \\ Governador Mangabeira-BA, Brasil.}

\section{Recebido em: 15/05/2020 - Aprovado em: 15/06/2020 - Publicado em: 30/06/2020} DOI: 10.18677/EnciBio_2020B51

\begin{abstract}
RESUMO
O trabalho teve como objetivo analisar o processo de desfazimento dos bens de $\mathrm{TI}$ inservíveis na Universidade Federal do Recôncavo da Bahia tendo como base o

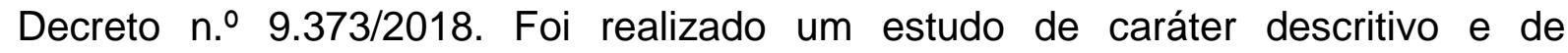
abordagem qualitativa, sendo delimitado como local de estudo a UFRB, especificamente a Coordenadoria de Material e Patrimônio e a Coordenadoria de Tecnologia da Informação. Os dados foram coletados através de análise documental, da realização de entrevistas semiestruturadas com membros das Coordenadorias, observação direta e registros fotográficos relativos ao manejo e destinação dos bens inservíveis de TI. Verificou-se que a universidade enfrenta entraves para garantir um fluxo adequado dos seus bens inservíveis de $\mathrm{TI}$, como exemplo: falta de infraestrutura física e pessoal para as atividades de gerenciamento; retardo nos trâmites burocráticos para doação dos equipamentos adquiridos com recursos de financiamento à pesquisa e extensão, pelas fundações de apoio; e as limitações do sistema de informações patrimoniais ora utilizado. Assim como, o não descarte de forma adequada de seus bens inservíveis de $\mathrm{TI}$,

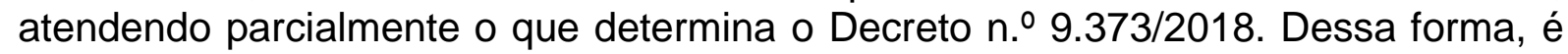
necessária uma proposta de um plano de ação para o desfazimento de bens inservíveis de TI que proporcione meios de fomentar políticas, projetos e ações de desfazimento sustentável, voltadas a ampliar as soluções para problemas socioambientais, consoante com as políticas nacionais, visando à mitigação do grande acúmulo dos bens nas instalações das Instituições Federais de Ensino Superior.
\end{abstract}

PALAVRAS-CHAVE: Descarte de bens inservíveis. Patrimônio Público. Sustentabilidade. 


\title{
DISPOSAL OF PERMANENT IT MOVABLE PROPERTY: PREPARATION OF AN ACTION PLAN PROPOSAL FOR THE FEDERAL UNIVERSITY OF THE RECÔNCAVO OF BAHIA - UFRB
}

\begin{abstract}
The objective of the work was to analyze the process of disposing of unserviceable IT assets at the Federal University of Recôncavo da Bahia, with a view to elaborating a proposal for an action plan to subsidize the disposal, based on Decree no 9.373/ 2018. A descriptive study with a qualitative approach was carried out, with UFRB as the study site, specifically the Material and Heritage Coordination and the Information Technology Coordination. Data collection was performed using semi-structured interview techniques with those responsible for the sector and observation regarding the handling and disposal of unserviceable IT assets, in addition to documentary analysis. It was found that the university faces obstacles to ensure an adequate flow of its unserviceable IT assets, as an example: lack of physical and personal infrastructure for management activities; delay in bureaucratic procedures for the donation of equipment acquired with funding for research and extension, by support foundations; and the limitations of the asset information system now used. The mandate of the Proposed Action Plan for the Disposal of IT Unserviceable Goods brings means to foster sustainable disposal policies, projects and actions, aimed at expanding solutions to socio-environmental problems, in accordance with national policies, aiming to mitigate the large accumulation assets on IFES premises. The results reveal that UFRB has not been able to properly dispose of its useless IT assets, partially complying with Decree $\mathrm{n}^{0}$ 9.373/2018.
\end{abstract}

KEYWORDS: Disposal of unserviceable assets. Public Patrimonial. Sustainability.

\section{INTRODUÇÃO}

A expansão das Universidades Federais por todo Brasil é uma consequência do Programa de Apoio a Planos de Reestruturação e Expansão das Instituições dessa natureza, o REUNI, projeto do Governo Federal que teve como meta principal ampliar o acesso e a permanência do cidadão brasileiro no ensino superior (REUNI, 2007).

É neste contexto que a UFRB, criada em 2005, entra em funcionamento em julho de 2006 e adere ao REUNI em 2007, logo após a implantação do programa. Assim, novos cursos e vagas foram abertos, possibilitando o crescimento da UFRB na região do Recôncavo da Bahia. Porém, uma das consequências desse aumento significativo da oferta é o crescente aumento dos bens patrimoniais dessas instituições autárquicas, principalmente os bens de $\mathrm{TI}$, o que passou a exigir da administração pública maior atenção e controle dos bens permanentes, ficando sobre a responsabilidade do setor de patrimônio (UFRB, 2011).

Após o fim da vida útil dos bens patrimoniais, especificamente os de TI, essas instituições se veem com centenas de máquinas e componentes eletroeletrônicos, para os quais precisa promover uma destinação social e ambientalmente adequada, minimizando os riscos potenciais, pois os equipamentos de TI apresentam, por vezes, constituintes tóxicos que, se liberados no meio, causam sérios danos à saúde humana e ao meio ambiente (REIDLER, 2012).

No sentido de mitigar os problemas causados pelos resíduos descartados diante da atividade produtiva que compromete o meio ambiente e a qualidade de

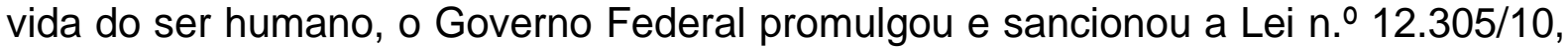
denominada Política Nacional de Resíduos Sólidos (PNRS) que, tem por objetivo em 
conjunto a NBR 10.004/04, caracterizar os resíduos sólidos como materiais, substâncias, objetos ou bens descartados resultantes das atividades humanas, econômicas, sociais ou culturais (atividades industriais, agrícolas, domésticas, comerciais, de atenção à saúde, limpeza urbana, dentre outras), podendo se apresentar nos estados sólido, semissólido, gasoso (desde que contidos em recipientes) ou liquido (cujas características não permitam o seu lançamento em redes de esgoto, corpos d'água ou que para isso exijam soluções técnicas ou economicamente inviáveis) (ABNT, 2004; BRASIL, 2010a).

Nesse sentido, com o passar dos anos, todo esse aparato mobiliário servível, principalmente o de tecnologia da informação, já que sofre, a todo instante, melhorias na qualidade e em formas de abordagens de relacionamento com sua clientela, deixa rapidamente de ser útil ao órgão possuidor, tornando-se 'inservível'. Essa denominação é atribuída aos bens que se encontram em estado ocioso, recuperável, antieconômico ou irrecuperável, não existindo razões para que estes continuem fazendo parte do patrimônio da instituição que o possui, devendo, portanto, ser feito o seu desfazimento de forma responsável e sustentável (Sistema de Gestão Patrimonial/UFRB-SIPAC, 2017).

Nesta perspectiva, este estudo teve como objetivo geral analisar a gestão de resíduos de TI da Universidade Federal do Recôncavo da Bahia, na perspectiva de elaborar um Plano de Ação para subsidiar o desfazimento de bens inservíveis de Tecnologia da Informação com base no Decreto n. 9 9.373/2018.

\section{MATERIAL E MÉTODOS}

A pesquisa se caracteriza como um estudo de caso, de natureza descritiva e abordagem qualitativa. Esta foi realizada na cidade de Cruz das Almas-BA, na Universidade Federal do Recôncavo da Bahia - UFRB, no Campus Cruz das Almas. A figura 1 delimita a área estudada no Campus Universitário da UFRB, respectivamente em duas Coordenadorias: Coordenadoria de Material e Patrimônio CMP e Coordenadoria de Tecnologia da Informação - COTEC.

FIGURA 1- Área de estudo na UFRB, no Campus Cruz das Almas.

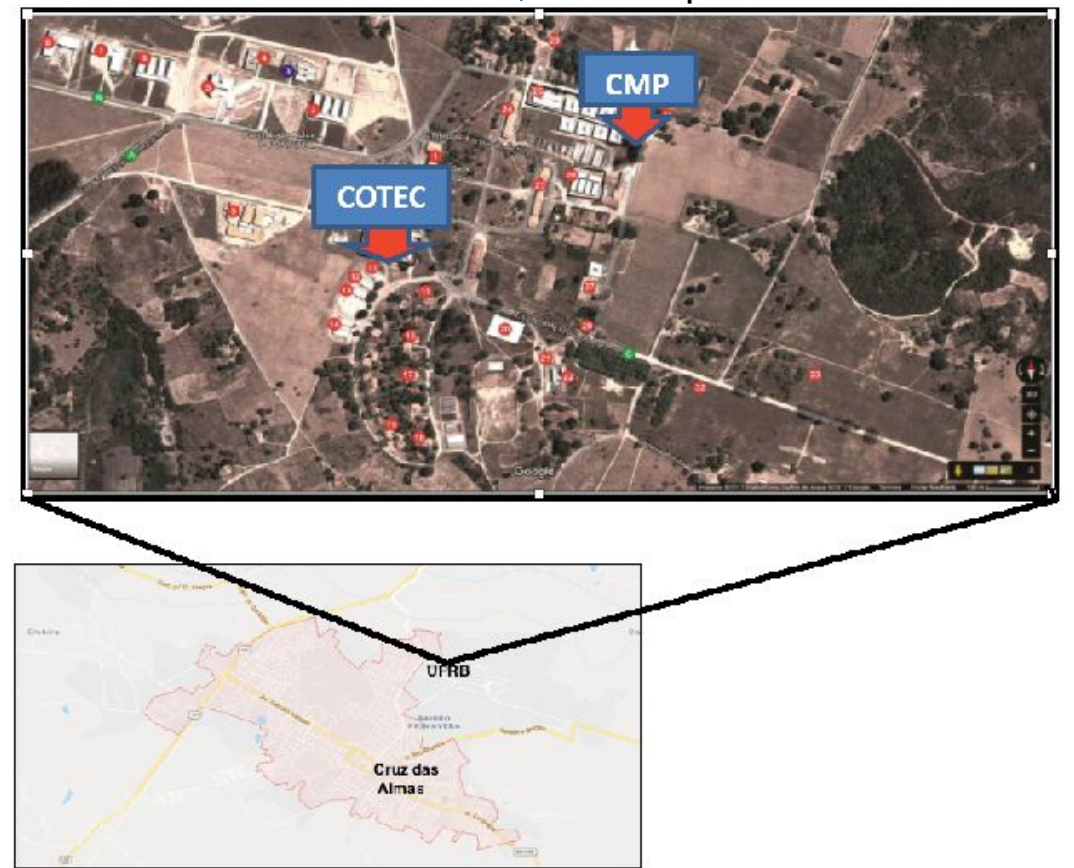

Fonte: Elaborado pelas autoras, (2018). 
A coleta dos dados foi desenvolvida em três momentos. Primeiramente foi feita análise documental nos relatórios e processos impressos e digitalizados do Sistema de Gestão Patrimonial (SIGEPAT, 2017) e, no Sistema Integrado de Patrimônio, Administração e Contratos (SIPAC), juntamente com o elemento de despesa e processos de doação de bens de TI da UFRB.

No segundo momento, foi aplicado questionários a cinco servidores da UFRB do Setor de Tl, sendo três servidores da Coordenadoria de Material e Patrimônio (coordenador, chefe do Núcleo de Gestão do Patrimônio e chefe de Núcleo de Manutenção de Bens Móveis) e dois servidores da Coordenadoria de Tecnologia da Informação (COTEC) (coordenado e chefe do Núcleo de Gestão de Atendimento aos Usuários (suporte técnico dos equipamentos de TI) e, concomitantemente, a realização de entrevistas não estruturadas (para complementar informações do questionário) com esses mesmos servidores. Para maior confiabilidade nos dados foram adotados os seguintes critérios de inclusão: servidor com no mínimo três anos de serviço na Instituição, ser lotado na CMP e COTEC. Como critério de exclusão: ser estagiário ou terceirizado, sendo que nenhum servidor foi excluído da pesquisa, pois todos atenderam aos critérios estabelecidos. Como forma de garantir o anonimato dos participantes do estudo, cada um recebeu como codinome "Servidor 1", "Servidor 2" e, assim, sucessivamente.

No terceiro momento foram feitas observação direta em campo nas áreas de armazenamento e destinação dos $\mathrm{TI}$, realizando-se registros fotográficos dos bens inservíveis em diferentes locais, sendo verificado estado de conservação dos bens de $\mathrm{Tl}$ e armazenamento. O estudo atendeu a Resolução 510/16, que garante o respeito pela dignidade humana e a proteção aos participantes do estudo, sendo avaliado por um Comitê de Ética e Pesquisa obtendo parecer favorável de $\mathrm{n}$. 2.716.472.

Os dados foram analisados a partir da técnica de análise temática de conteúdo (MINAYO, 2010), obedecendo as etapas: pré-análise, em que se fez uma leitura flutuante de todo o material coletado na investigação; a exploração do material em que se identificou expressões significativas relativas aos bens inservíveis de $\mathrm{Tl}$, em que emergiram as categorias: equipamentos de TI: origens e fluxos; destinação dos equipamentos de TI pós consumo na UFRB; potenciais impactos socioambientais do fluxo de resíduos de $\mathrm{Tl}$ e alguns entraves para o desfazimento sustentável de bens inservíveis de TI. Por fim o tratamento dos resultados e a interpretação, em que buscou-se estabelecer articulações entre os resultados encontrados e literatura existente sobre a temática.

\section{RESULTADOS E DISCUSSÃO \\ O PROCESSO DE CONTROLE DOS BENS PERMANENTES DE TI DA UFRB}

Em decorrência da heterogeneidade e do progresso na ciência da administração na área pública, cada vez mais despontam ferramentas capazes de tornar mais hábil e garantir melhores respostas nos métodos administrativos organizacionais. Estas valências são bem aceitas no atual contexto políticoeconômico-social brasileiro, onde se tornou necessário a contextualização de uma nova maneira de gerir os órgãos públicos, assegurando mais responsabilidade, transparência e celeridade para melhor responder aos interesses da sociedade (AZEVEDO et al., 2017).

Salienta-se que quando se fala em controle é necessário citar que é uma ferramenta efetiva de uma gestão. Desta maneira, o controle pode ser visto como um conjunto de ações, métodos e de rotinas que, tem por fundamento proteger o 
acervo patrimonial e agregar qualidade à gestão através de ações preventivas que compreendem o planejamento e avaliação periódica da atuação administrativa, dentro da mais absoluta legalidade (DORNELLES, 2009).

Assim, a UFRB para o correto desenvolvimento de suas atividades meio e fim, conta com um acervo patrimonial de $\mathrm{Tl}$, de acordo com informações extraídas do (SIPAC, 2018), composto por 11.972 itens, avaliado em $R \$ 7.631 .399,03$, que estão registrados em duas contas patrimoniais. Todos esses registros estão previstos pela Portaria $n .$. 448/2002, quanto à classificação dos bens móveis em material de consumo ou permanente, além da Instrução Normativa SRF n.o 162/1998 que complementa ao relatar sobre o período de utilidade estimando aos bens móveis (BRASIL, 1998; BRASIL, 2002).

Dentro destas características, Marques Junior et al. (2017) trazem que a boa gestão patrimonial é imprescindível para se ter retornos positivos, dentro do que é preconizado pela legislação, trazendo impactos na eficiência e efetividade da prestação dos serviços públicos. Porém, Nunes (2015) argumenta que ainda há dentro da gestão patrimonial das instituições públicas negligenciamento, sugerindo como medida para enfrentar o descaso com a gestão patrimonial, que estes setores disponham de recursos materiais, humanos e financeiros, para que atenuem a perda desses bens.

Segundo o Manual de Contabilidade Aplicada ao Setor Público - MCASP (BRASIL, 2017), os bens de TI são considerados como ativos imobilizados e estão sujeitos à depreciação no decorrer da sua vida útil. A manutenção adequada desses ativos não interfere na aplicação da depreciação. A apuração da depreciação deve ser feita mensalmente, a partir do momento em que o item do ativo se tornar disponível para uso, ou seja, quando está no local e em condição de funcionamento na forma pretendida pela administração. A depreciação cessa quando o ativo é baixado. Entretanto, não cessa quando o ativo se torna ocioso ou é retirado do uso.

FIGURA 2 - Representação do conceito de bens patrimoniais inservíveis.

\begin{tabular}{|c|c|c|c|c|c|c|}
\hline & $\begin{array}{l}\text { Resíduo } \\
\text { Sólido }\end{array}$ & & Bens Inservíveis & & $\begin{array}{c}\text { Bem } \\
\text { Patrimonial }\end{array}$ & $\begin{array}{l}\text { Bem Patrimonial } \\
\text { Inservível }\end{array}$ \\
\hline 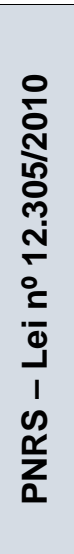 & $\begin{array}{l}\text { Qualquer } \\
\text { objeto, } \\
\text { material ou } \\
\text { bem } \\
\text { descartado, } \\
\text { oriundo da } \\
\text { atividade } \\
\text { humana }\end{array}$ & 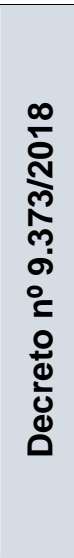 & $\begin{array}{l}\text { Material, objeto ou } \\
\text { bem descartado, } \\
\text { considerado } \\
\text { genericamente } \\
\text { inservível por não } \\
\text { ter sido } \\
\text { classificado } \\
\text { como ocioso, } \\
\text { recuperável, } \\
\text { antieconômico e } \\
\text { irrecuperável }\end{array}$ & 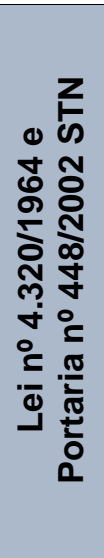 & $\begin{array}{l}\text { Bens e objetos, } \\
\text { incorporados } \\
\text { ao patrimônio } \\
\text { da entidade, } \\
\text { cuja duração é } \\
\text { superior a dois } \\
\text { anos }\end{array}$ & $\begin{array}{l}\text { Bens e objetos, } \\
\text { incorporados ao } \\
\text { patrimônio } \\
\text { entidades, } \\
\text { considerados } \\
\text { inservíveis por não } \\
\text { terem a destinação } \\
\text { adequada, e não } \\
\text { classificados como } \\
\text { ociosos, } \\
\text { recuperáveis, } \\
\text { antieconômico } \\
\text { irrecuperável, na } \\
\text { forma da lei. }\end{array}$ \\
\hline
\end{tabular}

Fonte: Dados da pesquisa, (2018)

\section{EQUIPAMENTOS DE TI NA UFRB: ORIGENS E FLUXOS}

Os equipamentos de TI da UFRB seguem um fluxo desde a sua origem até o seu destino. É importante salientar que o controle desses equipamentos é realizado pelos técnicos administrativos envolvidos no processo do acervo patrimonial. E, o melhor desempenho ocorre em função de servidores estarem inseridos no setor de patrimônio entre cinco a dez anos, garantindo maior conhecimento sobre o setor. 
Foi constatado que a Universidade Federal do Recôncavo da Bahia realizou inúmeras aquisições desde a sua implantação até o momento pela FAPEX e por processos licitatórios, de diversos equipamentos de $\mathrm{TI}$, utilizados, na realidade, em todas as suas atividades administrativas, de ensino, pesquisa ou extensão, principalmente os notebooks e desktops (computadores de mesa).

Existem várias formas de entrada e aquisição de equipamentos de TI pela UFRB. O trabalho focou em duas, por considerá-las de suma importância: aquisições realizadas por meio de projetos de pesquisa ou extensão desenvolvidos pela universidade e as aquisições institucionais, via compras por processos licitatórios empregando recursos próprios.

No que diz respeito às aquisições diretas dos equipamentos de $\mathrm{TI}$ pela universidade para suas atividades administrativas, montagens dos laboratórios de ensino, bibliotecas, dentre outros setores, o processo de compras obedece à Lei n.. 8.666/1993 (BRASIL, 1993), aplicada a todos os órgãos da Administração Pública Brasileira.

Quanto aos possíveis critérios de sustentabilidade incluídos na licitação para aquisição dos bens permanentes, verificou-se que a UFRB exige, em suas licitações na aquisição de equipamentos de $\mathrm{Tl}$, que os produtos não contenham substâncias perigosas ou prejudiciais ao meio ambiente e à saúde humana. $\mathrm{O}$ que ficou claro através da consulta ao formulário para avaliação técnica de fornecedores, utilizado em licitações para à aquisição de equipamentos de informática da UFRB, disponibilizado no Portal de Compras do Governo Federal (BRASIL, 2010b).

Constatou-se que essa exigência concretiza-se na forma da obrigatoriedade de apresentação de atestado de conformidade com as diretivas RoHS da União Europeia, proibindo a utilização de certas substâncias tóxicas, como o chumbo e o mercúrio, dentre os constituintes das máquinas. O critério adotado enquadra-se nas recomendações da Instrução Normativa $n . .01 / 2010$ do Ministério do Planejamento, Desenvolvimento e Gestão (MPDG) (BRASIL, 2010b). A universidade também considera a importância da aquisição de equipamentos com maior eficiência energética, o que se traduz em menores custos ao longo da vida útil do produto e um uso mais eficiente dos recursos públicos.

Quanto aos processos que envolvem esse fluxo dos equipamentos de TI sobre o encaminhamento desses equipamentos três respondentes salientaram que:

O equipamento é encaminhado pelo (a) usuário (a) para a Coordenadoria de Tecnologia da Informação (COTEC). Lá existe o Núcleo de Gestão de Atendimento aos Usuários (NUGAS) que é responsável pelo registro de entrada do bem, diagnóstico e manutenção dos computadores (Servidor 2).

São submetidos a COTEC/PROPLAN para avaliação. Os que tem mais condições de ser recuperados são armazenados por eles, os que são irrecuperáveis são encaminhados à CMP/PROAD para avaliação/desfazimento (Servidor 4).

São encaminhados ao atendimento para análise. A unidade executa o procedimento técnico de substituição do equipamento defeituoso (Servidor 5).

Quanto aos equipamentos de $\mathrm{TI}$ - notebooks, desktops, impressoras, entre outros, há manutenção corretiva, consequentemente, quando encerrada a garantia desses equipamentos que exibem algum defeito, são encaminhados para avaliação ao Núcleo de Gestão de Manutenção de Bens Móveis da universidade, se não 
houver condições de recuperação, são enviados ao Núcleo de Gestão do Patrimônio armazenados e conduzidos para o desfazimento (Figura 2).

FIGURA 3 - Fluxograma desfazimento para os equipamentos de TI da UFRB.

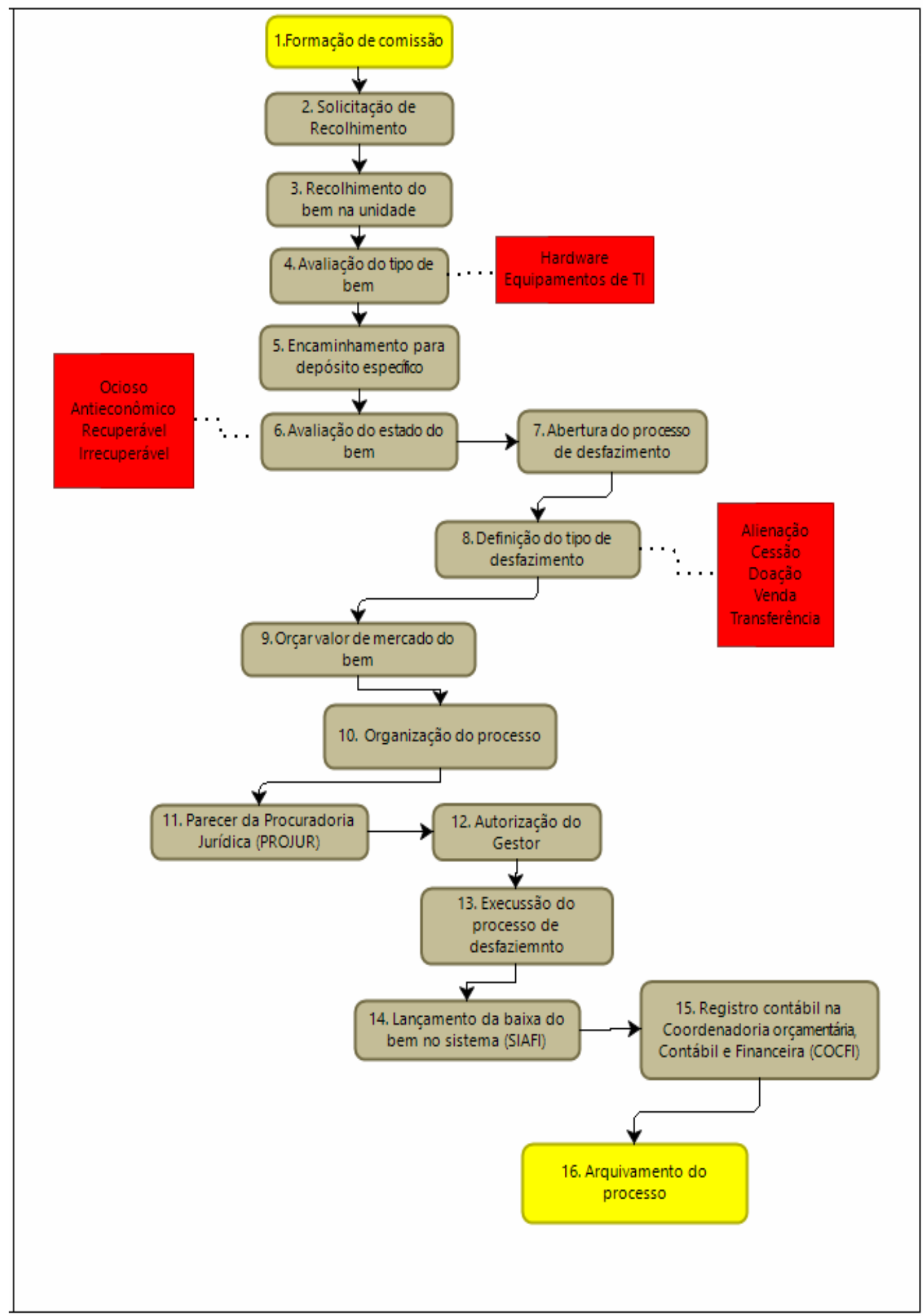

Fonte: Dados da pesquisa, (2018).

De acordo com a trajetória estabelecida através do fluxograma, o bem de TI passa por diversas etapas até a baixa patrimonial onde ficará arquivado o processo na Coordenadoria Orçamentária e Financeira - COCFI. Reforçando, Santos (2012) ENCICLOPÉDIA BIOSFERA, Centro Científico Conhecer - Goiânia, v.17 n.32; p. 583 
caracteriza esse tipo de gestão como conjunto de atividades que tem início com a compra de um bem, finalizando com a baixa do patrimônio da instituição.

\section{DESTINAÇÃO DOS EQUIPAMENTOS DE TI PÓS-CONSUMO NA UFRB}

Os equipamentos de TI, pós-consumo, na UFRB seguem as determinações de acordo com as legislações aplicáveis à administração de bens públicos e obedece a fluxos de entrada e saída, dependendo da natureza patrimonial do objeto, independente da forma de aquisição, seja com recursos próprios ou por meio de financiamento por órgãos de fomento que constituem os projetos de pesquisa como determinado em Brasil (2018a- UFRB, 224/11).

Para o desfazimento dos equipamentos de $\mathrm{TI}$ adquiridos com recursos próprios da universidade, pós-consumo, são seguidas as determinações estabelecidas no Decreto $n .0$ 9.373/2018, que regulamenta o reaproveitamento, a movimentação, a alienação ${ }^{2}$ e outras formas de desfazimento de bens, no âmbito da Administração Pública Federal (BRASIL, 2018b).

O Decreto n. ${ }^{\circ}$ 9.373/2018 elenca a classificação dos bens inservíveis desses órgãos nas categorias apresentadas no Quadro 1, neste apresenta-se também, com base nos achados da pesquisa, os destinos recomendados para cada um e como ocorre na UFRB.

QUADRO 1 - Classificação dos bens inservíveis e destinos de órgãos da Administração Pública Federal Brasileira e como ocorre na UFRB.

\begin{tabular}{|c|c|c|c|}
\hline CLASSIFICAÇÃO & DESCRIÇÃO & DESTINO INDICADO & $\begin{array}{c}\text { COMO OCORRE } \\
\text { NA UFRB }\end{array}$ \\
\hline Ocioso & $\begin{array}{l}\text { Bem em perfeitas } \\
\text { condições de uso, mas } \\
\text { que não esteja sendo } \\
\text { aproveitado pela } \\
\text { instituição. }\end{array}$ & $\begin{array}{l}\text { Doação para outro órgão ou } \\
\text { entidade da Administração } \\
\text { Pública Federal direta, } \\
\text { autárquica ou fundacional ou } \\
\text { para outro órgão integrante } \\
\text { de qualquer dos demais } \\
\text { Poderes da União. }\end{array}$ & $\begin{array}{l}\text { Transferência } \\
\text { entre setores. }\end{array}$ \\
\hline Recuperável & $\begin{array}{l}\text { Bem com defeito desde } \\
\text { que sua recuperação seja } \\
\text { possível e com custo } \\
\text { igual ou inferior a } 50 \% \text { de } \\
\text { seu valor de mercado }\end{array}$ & $\begin{array}{l}\text { Doação para outro órgão ou } \\
\text { entidade da Administração } \\
\text { Pública Federal direta, } \\
\text { autárquica ou fundacional ou } \\
\text { para outro órgão integrante } \\
\text { de qualquer dos demais } \\
\text { Poderes da União. }\end{array}$ & $\begin{array}{l}\text { Envio para o } \\
\text { NUGBMÓVEIS, } \\
\text { realizar a } \\
\text { manutenção } \\
\text { quando possível. }\end{array}$ \\
\hline Antieconômico & $\begin{array}{l}\text { Bem cuja manutenção é } \\
\text { tida como onerosa e o } \\
\text { rendimento e precário, } \\
\text { em virtude de uso } \\
\text { prolongado, desgaste } \\
\text { prematuro ou } \\
\text { obsoletismo. }\end{array}$ & $\begin{array}{l}\text { Doação para Estados e } \\
\text { Municípios mais carentes, } \\
\text { Distrito Federal, empresas } \\
\text { públicas, sociedade de } \\
\text { economia mista, instituições } \\
\text { filantrópicas, reconhecidas de } \\
\text { utilidade pública pelo } \\
\text { Governo Federal, e } \\
\text { Organizações da Sociedade } \\
\text { Civil de Interesse Público } \\
\text { (OSCIP). }\end{array}$ & $\begin{array}{l}\text { Envio para o } \\
\text { NUGPAT realizar } \\
\text { o seu devido } \\
\text { descarte } \\
\text { conforme } \\
\text { previsto no } \\
\text { Decreto } \\
\text { n. } 9.373 / 2018 \text {. }\end{array}$ \\
\hline
\end{tabular}

\footnotetext{
${ }^{2}$ Segundo o Decreto $n^{\circ} 9.373 / 2018$, a alienação de bens consiste na operação de transferência do direito de propriedade do material, mediante venda, doação ou permuta.
} 
Irrecuperável

Bem com defeito, nãorecuperável ou cuja recuperação seja inviável economicamente
Doação para instituições filantrópicas, reconhecidas de utilidade pública pelo

Governo Federal, e as Organizações da Sociedade Civil de Interesse Público (OSCIP).
Envio para o

NUGPAT realizar

o seu devido

descarte

conforme

previsto no

Decreto

n. $.9 .373 / 2018$.

Fonte: Dados da pesquisa, (2018).

Para os equipamentos de $\mathrm{TI}$, ociosos e recuperáveis, o novo Decreto abre uma exceção aos possíveis destinos indicados no Quadro 1, permitindo que os mesmos sejam doados diretamente pela instituição (Quadro 2) excepcionalmente, mediante ato motivado pelo Magnífico Reitor para as Organizações da Sociedade Civil de Interesse Público (OSCIPs).

O novo decreto que trata de desfazimento, também traz claramente em seu art. $8^{\circ}$, inciso III combinado com o parágrafo único, no que diz respeito à exigência para escolha das entidades receptoras dos bens inservíveis de TI, classificado como irrecuperável. Os órgãos públicos federais, conforme previsto no art. 14, do mesmo decreto, só podem realizar a doação as Organizações da Sociedade Civil de Interesse Público, Associações ou Cooperativas, que atendam aos requisitos pré-

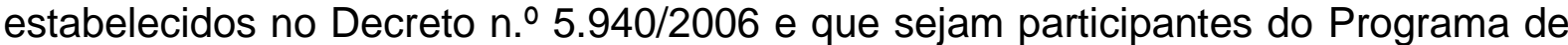
Inclusão Digital do Governo Federal, conforme disciplinado pelo Ministério da Ciência, Tecnologia, Inovações e Comunicações (BRASIL 2018b).

O Centro de Recondicionamento de Computadores (CRC), é um espaço físico adaptado para o recondicionamento de equipamentos de $\mathrm{Tl}$ e para a realização de cursos e oficinas, visando à formação cidadã e profissionalizante de jovens em situação de vulnerabilidade social com foco no processamento de equipamentos de informática usados, de modo a deixá-los em plenas condições de funcionamento, sendo assim, a ação de apoio ao CRC envolve também a Administração Pública Federal na oferta de equipamentos recondicionados.

Assim, conforme apresentado anteriormente, as entidades receptoras dos bens de $\mathrm{Tl}$, também precisam atender a uma série de critérios que abrangem desde a sua qualificação como instituição de utilidade pública ou OSCIP, a existência de uma autonomia administrativa e financeira, aliada a uma infraestrutura física e de pessoal técnico, para condução dos trabalhos e cadastro no Sistema Integrado de Monitoramento (SIMMC). Atualmente só existem 07 (sete) Centros atuando em todo o território brasileiro, um deles é instalado na Universidade Federal do Vale do São Francisco - UNIVASF, que funciona no Espaço Plural, em Juazeiro - BA (BRASIL, 2018a).

QUADRO 2 - Tipos e quantidades de equipamentos de TI doados pela UFRB.

EQUIPAMENTOS OU COMPONENTES

CPU's

Monitores

TOTAL

\section{QUANTIDADE (UNIDADE)}

40

40

80

Fonte: Dados da pesquisa, (2018). 
Como consequência, tem-se a superlotação do espaço utilizado e o armazenamento dos materiais de forma inadequada, de maneira geral, amontoados uns por cima dos outros, já que se trata de um lixo tóxico, volumoso e de difícil acondicionamento, e que ocupa grandes espaços físicos.

Com o advento do novo Decreto, o governo teve a preocupação de compartilhar a responsabilidade, entre os alienatários e beneficiários no ato da transferência, no que diz respeito à destinação final ambientalmente adequada dos

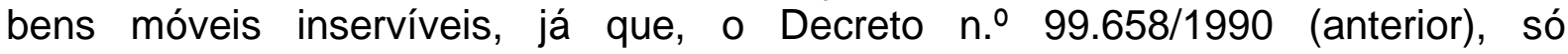
responsabilizava a entidade doadora, e com a inovação da legislação (Decreto $n .^{\circ}$ 9.373/2018), tanto os alienatários e beneficiários se responsabilizarão, ou seja, realizarão a responsabilidade compartilhada.

\section{POTENCIAIS IMPACTOS SOCIOAMBIENTAIS DO FLUXO DE RESÍDUOS DE TI NA UFRB}

Sabe-se que a literatura, traz que muitos equipamentos eletroeletrônicos, incluindo os de TI, possuem inúmeras substâncias perigosas, inclusive os metais pesados, e que podem ser liberadas para o meio quando da ocorrência de um manejo inadequado que implique no rompimento de alguns dos seus componentes, oferecendo riscos à saúde pública e ao meio ambiente (LUNARDI et al., 2014). Assim, uma das soluções para evitar esse acúmulo é uma possível alienação de bens, conforme previsto no art. $7^{\circ}$ da Lei n. ${ }^{\circ}$ 8.666/1993 (BRASIL, 1993).

Nos registros fotográficos, ficou evidenciado que as condições de armazenagem nas instalações da IFES não apresentam maior cuidado na disposição (Figura 3).

FIGURA 4-Bens inservíveis expostos no galpão do DNIT/UFRB, Cruz das AlmasBA.

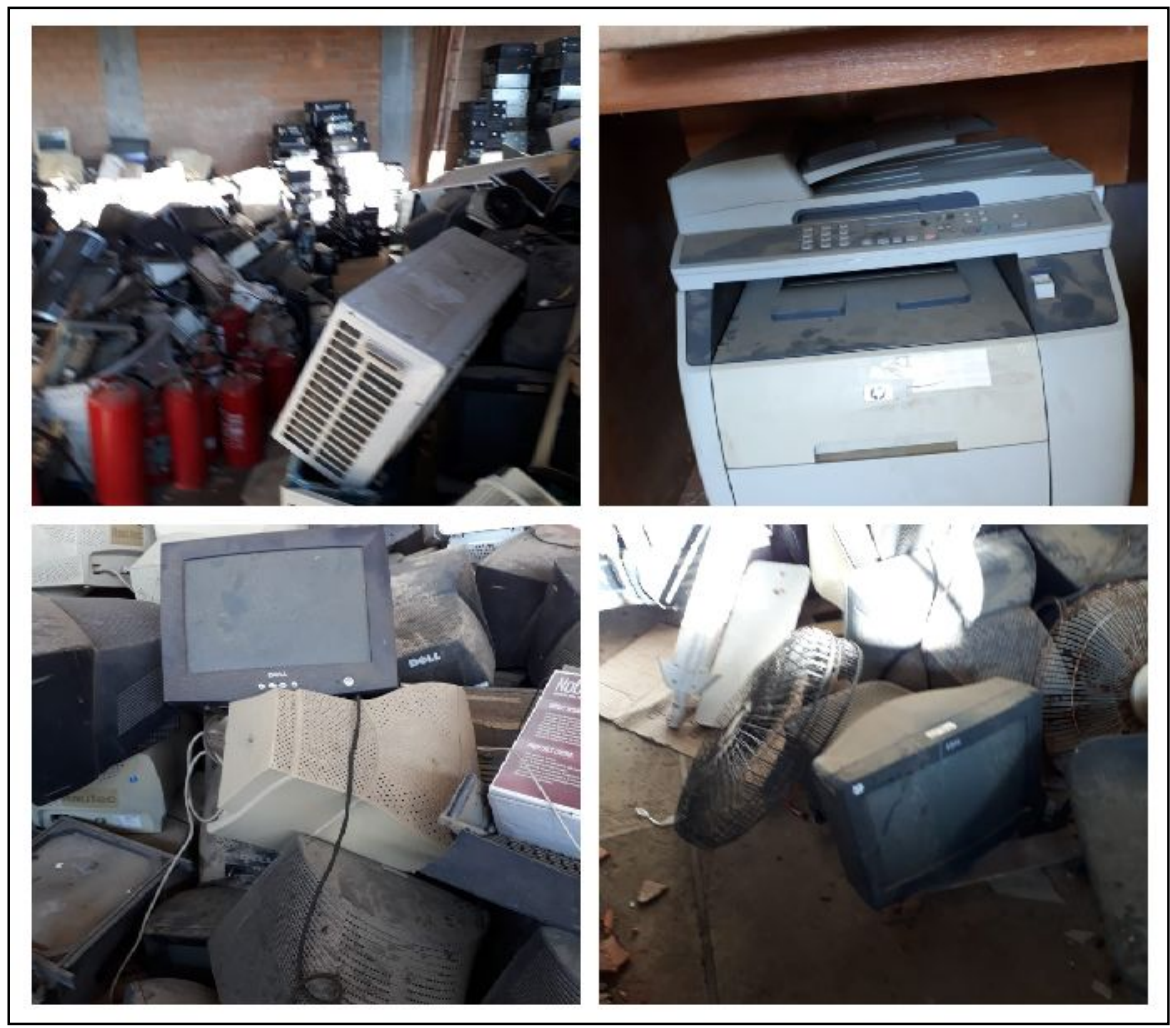

Fonte: Dados da pesquisa, (2018). 
Ficou evidente que bens inservíveis são armazenados expostos ao tempo, propiciando assim à proliferação de insetos, roedores e animais peçonhentos, expondo às pessoas a convivência em área insalubre, além da possibilidade de afetar o meio com substâncias tóxicas oriundas de vazamentos dos equipamentos.

FIGURA 5 - Condições de armazenagens dos bens inservíveis da UFRB nas dependências da antiga sede do CCAAB/UFRB, Cruz das Almas-BA.

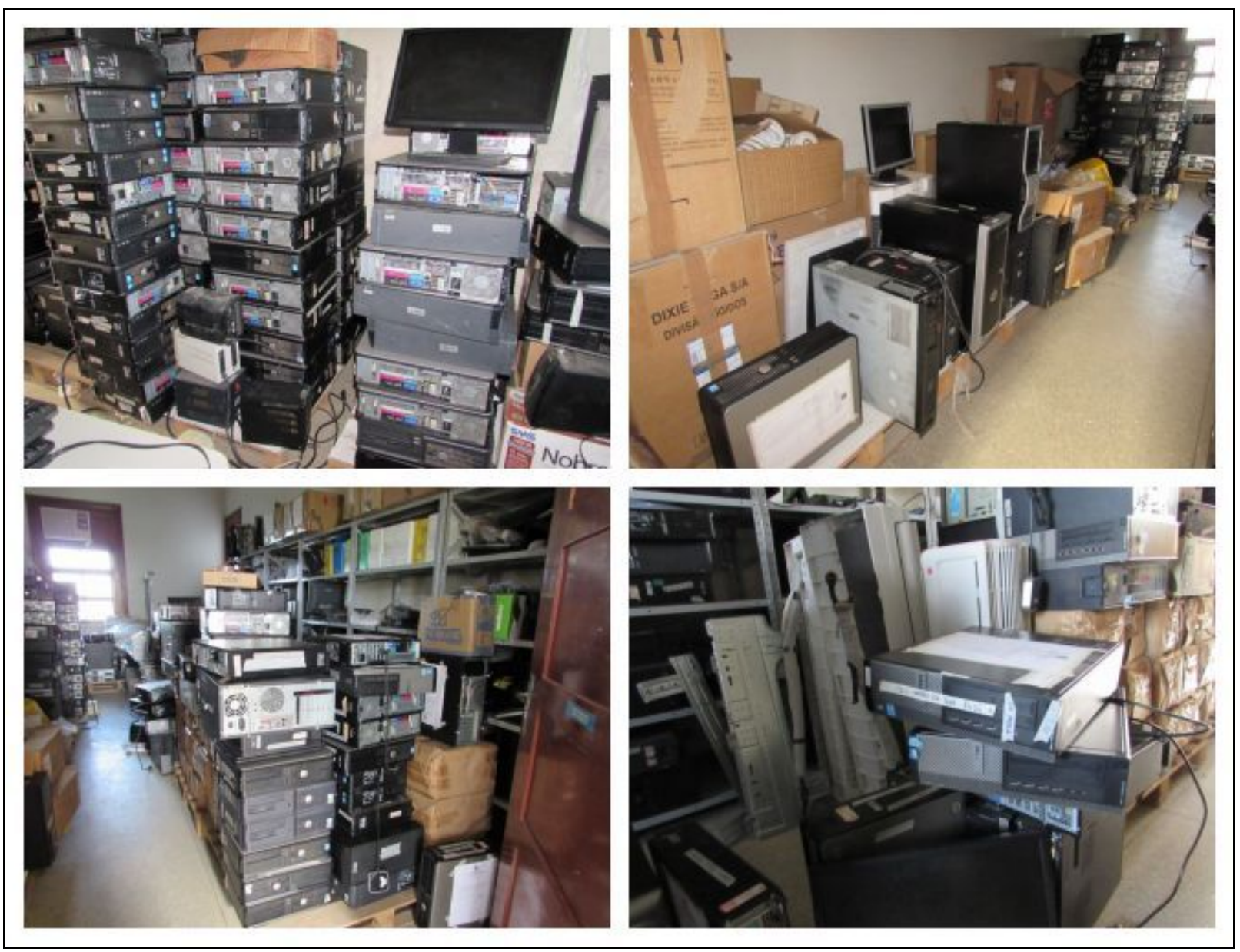

Fonte: Dados da pesquisa, (2018).

Percebeu-se nos relatos dos servidores que existem espaços destinados para armazenamento, porém, há a necessidade de áreas específicas para cada tipo de bens inservíveis, mesmo porque a CMP e o NUGPAT tem autonomia e alternativas (do tratamento ou desfazimento), sendo o Setor de Patrimônio o mais estreitamente ligado com a problemática dos resíduos, já que, os bens patrimoniados não podem ser descartados sem a prévia avaliação e autorização do Magnífico Reitor, conforme previsão legal (BRASIL, 2018a).

\section{ALGUNS ENTRAVES PARA O DESFAZIMENTO SUSTENTÁVEL DE BENS INSERVÍVEIS DE TI NA UFRB}

Os obstáculos encontrados pelos gestores públicos em lidar com situações de gerenciamento dos resíduos sólidos no âmbito institucional, e até mesmo estar em consonância com a PNRS, criam barreiras que são necessárias de serem vencidas pela Administração Pública em geral. A retirada de bens inservíveis de TI de uma Instituição Federal de Ensino Superior requer uma série de procedimentos legais ENCICLOPÉDIA BIOSFERA, Centro Científico Conhecer - Goiânia, v.17 n.32; p. 587 2020 
vigentes. Uma das formas para esse processo é através da modalidade de Licitação, chamada Leilão, prevista no Decreto n. ${ }^{\circ}$ 9.373/2018 (BRASIL, 2018b).

Assim, buscou-se listar as principais dificuldades e deficiências identificadas no modelo da atual gestão, baseando-se nas informações obtidas através dos entrevistados e documentos (Quadro 3).

QUADRO 3 - Entraves identificados para uma gestão sustentável de resíduos de TI na UFRB, Cruz das Almas.

\section{ENTRAVES NA GESTÃO}

Dificuldades na gestão, pósconsumo, de equipamentos adquiridos com recursos dos projetos de pesquisa e extensão.

Dificuldades para a doação de equipamentos para reutilização em outros órgãos públicos ou projetos de interesse social.

Dificuldades infraestruturais para a gestão dos resíduos.

Dificuldades com o sistema de informações do setor de patrimônio.

\section{PRINCIPAIS DESAFIOS}

a) Retardo na transferência por doação dos bens dos projetos de pesquisa entre as instituições (falta de articulação entre a Universidade e as instituições fomentadoras dos recursos financeiros);

b) Inexistência de normatização, através de um Manual de Procedimentos, de forma clara para a gestão desses bens, pósconsumo, na Universidade, causando dúvidas e desinformação, qual o fluxo correto para o descarte sustentável.

c) Falta de informação ou de interesse para solicitar a doação e/ou falta de pessoal, de infraestrutura para recolher, triar e distribuir os bens, a prefeituras e outros órgãos públicos mais carentes;

d) Rigidez e excesso de trâmites burocráticos impostos pelo Decreto n‥ 9.373/18 e outras legislações, para transferência de bens na Administração Pública Federal;

e) Inexistência de espaço físico e pessoal técnico administrativo disponibilizado para a rotina da gestão dos equipamentos de TI, pós-consumo, incluindo, no mínimo, o transporte, recepção, triagem, classificação e acondicionamento adequado dos bens inservíveis;

f) Plataforma desatualizada e pouca flexibilidade na geração de relatórios, dificultando uma interpretação mais completa e integrada dos dados existentes;

g) Não permite o conhecimento da destinação final dada aos bens inservíveis da UFRB, após alienação.

Fonte: Dados da pesquisa, (2018).

Diante do exposto, o processo de habilitação, traz uma cadeia sucessiva de exigências, que acaba causando barreira, ou até paralisam, o reaproveitamento dos bens inservíveis de $\mathrm{TI}$, que, por vezes acabam sendo descartados de maneira ambientalmente incorreta, ao invés de serem aproveitados em projetos de interesse social.

\section{CONCLUSÃO}

Os resultados revelam que a UFRB, no que se refere à CMP e a COTEC, não vem conseguindo dinamizar, de forma eficiente e ambientalmente sustentável, o processo de desfazimento dos bens inservíveis de $\mathrm{TI}$, para que se evite concentração de bens de TI inservíveis em espaços físicos desapropriados. Quanto ao processo de controle dos bens permanentes de $\mathrm{TI}$, a maioria é oriunda de compras e doações, porém estes necessitam que estas ocorram de forma mais célere, impedindo o acúmulo excessivo e a deterioração dos bens inservíveis de $\mathrm{TI}$ da IFES.

Nesse contexto, urge a minimização de dificuldades enfrentadas para promover a doação dos bens inservíveis de $\mathrm{TI}$ em desuso para a reutilização na própria IFES ou em outros órgãos da Administração Pública ou projetos sociais de inclusão digital. Assim, a doação em tempo hábil favoreceria solucionar o problema 
da destinação final adequada dos equipamentos de TI pós-consumo. Quanto às dificuldades encontradas no processo do desfazimento dos bens inservíveis de $\mathrm{TI}$ foram citadas a falta de eficiência devido a burocratização e morosidade dos processos, sendo impedimento para uma gestão mais sustentável desses. Constatou-se que o excesso de exigências e a demora do trâmite processual dificultam a transferência de bens do acervo patrimonial da UFRB para outros órgãos públicos ou para projetos de interesse social, o que, por vezes, impossibilita a doação de equipamentos de TI ainda em condições de uso, por ser um bem permanente que sofre rápida obsolescência.

Nessa perspectiva, espera-se, que uma proposta do Plano de Ação seja efetivamente útil, utilizando-o como um guia, ou seja, que sirva como roteiro dos procedimentos a serem seguidos pela Comissão Especial, com o intuito de efetuar a destinação ambientalmente sustentável dos bens inservíveis da Instituição

\section{REFERÊNCIAS}

ABNT, Associação Brasileiras de Normas Técnicas. NBR 10.004: Resíduos sólidos - Classificação. Rio de Janeiro, 2004, 71 p.

AZEVEDO, T. C. B.; ALTAF, J. G.; TROCCOLI, I. R.. O controle patrimonial na administração pública. Revista Eletrônica Machado Sobrinho, Juiz de Fora, v. 13, n. 01, p.01-09, ago. 2017.

BRASIL. Ministério da Ciência, Tecnologia, Inovações e Comunicações. Centro de recondicionamento de computadores. Brasília, 2018a. Disponível em: http://www.mctic.gov.br/mctic/opencms/comunicacao/SETEL/inclusao_digital/CRCs/ CRCs.html?searchRef=centro\%20de\%20recondicionamento\%20de\% $\overline{20}$ computador es. Acesso em: 10 jul. 2018.

BRASIL. Decreto n. 9.373 de 11 de maio de 2018b. Dispõe sobre a alienação, a cessão, a transferência, a destinação e a disposição final ambientalmente adequada de bens móveis no âmbito da administração pública federal direta, autárquica e fundacional. Diário Oficial da Republica Federativa do Brasil, Brasília, 2018b. Disponível

em: http://legis.senado.gov.br/legislacao/DetalhaSigen.action?id=26897546. Acesso em: 11 jul. 2018.

BRASIL. Lei no 8.666, de 21 de junho de 1993. Diário Oficial da República Federativa do Brasil, Brasília, 22 jun. 1993, republicada em 06 jul. 1994. Disponível em: http://www.planalto.gov.br/ccivil_03/leis//8666cons.htm. Acesso em: 03 out. 2017.

BRASIL, Ministério da Economia. Secretaria da Receita Federal. Instrução Normativa no 162, de 31 de dezembro de 1998. Fixa prazo de vida útil e taxa de depreciação dos bens que relaciona. Disponível em: http://normas.receita.fazenda.gov.br/sijut2consulta/link.action?idAto=15004\&visao $=0$ Acesso em: 03 out. 2016.

BRASIL. Ministério do Planejamento, Orçamento e Gestão. Secretaria de Logística e Tecnologia da Informação. Instrução Normativa no 01, de 19 de janeiro de 2010a. Regulamenta a utilização de critérios sustentáveis na compra de bens e na 
contratação de obras e serviços pelo Governo Federal. Brasília, 2010a. Disponível em:http://www.comprasgovernamentais.gov.br/paginas/instrucoes-

normativas/instrucaonormativa-no-01-de-19-de-janeiro-de-2010. Acesso em: 05 out. 2016.

BRASIL. Lei no 12.305, de 02 de agosto de 2010b. Diário Oficial da República Federativa do Brasil, Brasília, 03 ago. 2010b. Disponível em:

http://www. planalto.gov.br/ccivil_03/_ato2007-2010/2010/lei/l12305.htm. Acesso em: 03 out. 2017.

BRASIL. Portaria № 448, de 13 de setembro de 2002. Diário Oficial da República Federativa do Brasil, Brasília, 17 set. 2002. Disponível em: <http://www3.tesouro.fazenda.gov.br/legislacao/download/contabilidade/Port_448_2 002. pdf>. Acesso em: 08 out. 2016

BRASIL. Secretaria do Tesouro Nacional. Manual de Contabilidade Aplicada ao Setor Público (MCASP): aplicado à União e aos Estados, Distrito Federal e Municípios. 7. ed. Brasília: Secretaria do Tesouro Nacional, 2017. Disponível em: http://www.tesouro.fazenda.gov.br/documents/10180/456785/MCASP+7\%C2\%AA\% 20edi\%C3\%A7\%C3\%A3o+Vers\%C3\%A3o+Final.pdf/6e874adb-44d7-490c-8967b0acd3923f6d. Acesso em: 11 dez. 2017.

DORNELLES, G. M. R.. Controle interno na Administração Pública. 2 ed. Porto Alegre, 2009.

LUNARDI, G. L.; SIMÕES, R.; FRIO, R. S.. TI verde: uma análise dos principais benefícios de práticas utilizadas pelas organizações. REAd, Porto Alegre, v. 1, n. 77, p.1-30, abr. 2014.

MARQUES JUNIOR, E. L.; FEITOSA, L. V. S.; CAVALCANTE, J. C. A.; DANTAS, C. V.; SOUZA, W. A. R.; COSTA, A. C. S. Gestão de bens inservíveis em uma instituição de ensino superior do nordeste brasileiro. Revista de Administração e Negócios da Amazônia, v. 9, n. 4, p. 38-66, 2017.

MINAYO, M.C.S. O Desafio do Conhecimento: Pesquisa Qualitativa em Saúde. 29. ed. São Paulo: Hucitec, 2010.

NUNES, L. C. M. O emprego da teoria agente/principal para definição de modelo de gestão de bens móveis na Universidade de Brasília. 2015. Dissertação (Mestrado Profissional em Gestão Pública) - Universidade de Brasília, Brasília, 2015.

REIDLER, N. M. V. L. Resíduos de equipamentos elétricos e eletrônicos em instituições de ensino superior: estudo de caso sobre diretrizes para elaboração de plano de gestão integrada. Tese (Doutorado), Programa de Pós-Graduação em Saúde Pública, Universidade de São Paulo. São Paulo-SP, 2012. Disponível em: file:///Users/andrea/Downloads/Tese_Nivea_Reidler\%20(1).pdf. Acesso em: 11 out. 2017. 
REUNI. Reestruturação e Expansão das Universidades Federais. Plano de Desenvolvimento da Educação. Portaria no 552 SESu/MEC, de 25 de junho de 2007, em complemento ao art. 1 $§ 2^{\circ}$ do Decreto Presidencial $n \circ 6.096$, de 24 de abril de 2007. Brasília, 2007. Disponível em: http://portal.mec.gov.br/sesu/arquivos/pdf/diretrizesreuni.pdf. Acesso em: 20 out. 2017.

SANTOS, G. Gestão patrimonial: ampliada e atualizada. 4 ed. Florianópolis: Secco, 2012.

SIGEPAT - Sistema de Gestão Patrimonial/UFRB. 2017. Disponível em: https://ufrb.edu.br/portal/. Acesso em: 20 mai. 2017.

SIPAC - Sistema Integrado de Patrimônio, Administração e Contratos/UFRB, 2017. Disponível em: https://ufrb.edu.br/portal/. Acesso em: 20 jul. 2018.

UFRB. Universidade Federal do Recôncavo da Bahia. Portaria no 224, de 09 de maio de 2011. Institui as normas de registro e controle dos bens patrimoniais móveis da Universidade Federal do Recôncavo da Bahia. Cruz das Almas, 09 maio 2011. 